\title{
Overdrainage-related ependymal bands: a postulated cause of proximal shunt obstruction
}

\author{
Mark R. Kraemer, MD, ${ }^{1}$ Joyce Koueik, MD, ${ }^{1}$ Susan Rebsamen, MD, ${ }^{2}$ David A. Hsu, MD, PhD, ${ }^{3}$ \\ M. Shahriar Salamat, MD, PhD, ${ }^{1,4}$ Susan Luo, BS, ${ }^{1}$ Sara Saleh, MD, ${ }^{1}$ Taryn M. Bragg, MD, ${ }^{5}$ and \\ Bermans J. Iskandar, MD'1
}

Departments of ${ }^{1}$ Neurosurgery, ${ }^{2}$ Radiology, ${ }^{3}$ Neurology, and ${ }^{4}$ Pathology, University of Wisconsin Hospitals and Clinics, Madison, Wisconsin; and ${ }^{5}$ Department of Neurosurgery, Phoenix Children's Hospital, Phoenix, Arizona

OBJECTIVE Ventricular shunts have an unacceptably high failure rate, which approaches $50 \%$ of patients at 2 years. Most shunt failures are related to ventricular catheter obstruction. The literature suggests that obstructions are caused by in-growth of choroid plexus and/or reactive cellular aggregation. The authors report endoscopic evidence of overdrainage-related ventricular tissue protrusions ("ependymal bands") that cause partial or complete obstruction of the ventricular catheter.

METHODS A retrospective review was completed on patients undergoing shunt revision surgery between 2008 and 2015, identifying all cases in which the senior author reported endoscopic evidence of ependymal tissue in-growth into ventricular catheters. Detailed clinical, radiological, and surgical findings are described.

RESULTS Fifty patients underwent 83 endoscopic shunt revision procedures that revealed in-growth of ventricular wall tissue into the catheter tip orifices (ependymal bands), producing partial, complete, or intermittent shunt obstructions. Endoscopic ventricular explorations revealed ependymal bands at various stages of development, which appear to form secondarily to siphoning. Ependymal bands are associated with small ventricles when the shunt is functional, but may dilate at the time of obstruction.

CONCLUSIONS Ventricular wall protrusions are a significant cause of proximal shunt obstruction, and they appear to be caused by siphoning of surrounding tissue into the ventricular catheter orifices.

https://thejns.org/doi/abs/10.3171/2018.5.PEDS18111

KEYWORDS hydrocephalus; shunt malfunction; CSF overdrainage; ventricular catheter obstruction; surgical technique

$\mathrm{M}$ ECHANICAL CSF diversion has benefited countless hydrocephalic children and adults. ${ }^{26}$ Yet, shunts are plagued with high failure and complication rates, ${ }^{5,6}$ and many of the patients experience debilitating headaches; ${ }^{31}$ only a minority live an asymptomatic and shunt revision-free life. ${ }^{35}$

Randomized controlled trials have demonstrated shunt failure rates nearing $40 \%$ at 1 year and $50 \%$ at 2 years. ${ }^{8,19,20}$ Long-term retrospective studies show that more than $80 \%$ of patients with shunts will require at least 1 shunt revision within 12 years of placement, ${ }^{35,38}$ with minimal improvement in these statistics in recent studies. ${ }^{22}$ Shunt malfunctions lead to serious consequences, including long-term disability and death. ${ }^{1,9,17}$ The most common cause of shunt malfunction is mechanical obstruction, with the majority of obstructions involving the ventricular catheter. ${ }^{8}$ Few high-quality studies have identified factors associated with obstructive shunt failure: The Shunt Design Trial ${ }^{8,20}$

ABBREVIATIONS ETV = endoscopic third ventriculostomy; FOHR = frontal occipital horn ratio; IVH = intraventricular hemorrhage.

SUBMITTED February 26, 2018. ACCEPTED May 22, 2018.

INCLUDE WHEN CITING Published online August 17, 2018; DOI: 10.3171/2018.5.PEDS18111. 
and Endoscopic Shunt Insertion Trial ${ }^{19}$ are multicenter, randomized control studies that demonstrate the extent to which modern interventions, particularly valve technology and shunt endoscopy, are ineffective in improving the rate of shunt failure.

Little is known about the underlying pathophysiology of ventricular catheter obstructions. While recent literature hypothesizes a reactive process occurring in response to the foreign catheter material, ${ }^{12-14,37}$ a survey of the senior pediatric neurosurgical community shows wide discrepancies among surgeons' understanding of this problem. These discrepancies appear to arise from a lack of highquality evidence and inconsistent knowledge of existing literature. ${ }^{21}$ Interestingly, common to all these theories is the yet ill-defined observation that tissue, cellular debris, or reactive processes lodge in the ventricular catheter.

At our center, ventricular endoscopy is used to guide most shunt revision procedures. We report distinctive pathological changes to the ventricular walls ("ependymal bands") surrounding the catheter tip that occur in many endoscopic ventricular examinations of patients with proximal shunt occlusion. These changes consist of tissue protrusions into the catheter orifices that occlude the catheters intermittently, partially, or completely. The morphology of the ependymal bands appears to correlate with the age of the catheter and the severity of the obstruction. Importantly, ependymal bands occur primarily in patients whose ventricles appear small on imaging studies obtained when the shunt is functional; intraoperative experimental occlusion of the ventricular catheter in select patients reverses the catheter obstruction, indicating a close association with active CSF drainage. Taken together, these observations indicate that shunt overdrainage plays a critical role in proximal shunt malfunction.

\section{Methods}

\section{Patient Selection and Treatment Approach}

After obtaining approval for the study from the University of Wisconsin IRB, a retrospective review was completed on pediatric and adult hydrocephalic patients with ventricular shunts undergoing endoscopic surgery at the University of Wisconsin Hospital and American Family Children's Hospital between 2008 and 2015. Cases in which ependymal bands were observed endoscopically and documented in the senior author's (B.J.I.) prospective surgical database were identified. Most shunt revisions were performed urgently in patients with acute shunt malfunction, and some were performed nonurgently for other clinical reasons. The majority of, but not all, patients underwent imaging, usually in the form of a CT scan or short-sequence ("quick-brain") MRI as previously described..$^{16}$ Shunts were tapped when the diagnosis of shunt malfunction was not evident on imaging, or to rule out infection, as previously described.$^{33}$ Patients with clinical symptoms, imaging, and/or shunt tap findings consistent with shunt malfunction underwent surgical shunt exploration. Indications for nonurgent endoscopic ventricular or shunt surgery included endoscopic third ventriculostomy (ETV) to achieve shunt independence, reestablishment of shunt function after ETV failure, and shunt replacement or removal for infection management. All operative interventions were completed by the senior author.

\section{Endoscopic Shunt Revision Surgery}

At our institution, the scalp incision is opened and the proximal catheter disconnected from the valve. The distal system is then tested using a manometer. In the presence of normal distal runoff, the distal catheter and valve are deemed patent. The ventricular catheter is visually inspected for evidence of spontaneous CSF and manually assessed for adherence to brain tissue. In some cases, a 1-mm nondisposable endoscope with accompanying cannula (ClarusScope and ShuntPen cannula, respectively; Clarus Medical) is introduced into the ventricular catheter for ventricular exploration and to search for an obstruction. In other cases, a rigid $2.7-\mathrm{mm}$ glass rod endoscope is introduced along the catheter through the shunt tract. The proximal catheter is considered obstructed when either a full or significant occlusion of the catheter is observed, or if the catheter is found to be adherent to brain tissue with little to no spontaneous CSF flow. In some cases of ventricular catheter adherence, coagulation through a stylet is used to release the adhesions. In other cases, the adhesions are released via endoscopic exploration external to the catheter. Endoscopic media obtained from each case were stored on a secure hard drive for retrospective review. Abnormal ventricular tissue findings were categorized as mild, moderate, and severe based on gross appearance and findings detailed in the operative report. Further detail is described in the Results section.

\section{Radiological Evaluation}

We systematically analyzed CT and MR scans (mainly "quick-brain" MRI) for all cases. Where available, two types of scans were reviewed for each surgical episode: a preoperative (i.e., shunt failure) scan and a baseline scan. "Shunt failure" scans were mostly obtained immediately before urgent surgery. However, in some cases when asymptomatic shunt malfunction had been detected on surveillance imaging at routine office visits, the scans often preceded the surgery by days to weeks. "Clinically baseline" scans were completed weeks to months before surgery on outpatient surveillance imaging, or alternatively at emergency visits when the patient's shunt was deemed functional by the neurosurgery consultant. An imaging classification system was used to evaluate the local ventricular environment surrounding the proximal catheter tip (Table 1), as reported previously.,40 For all scans, ventricular dilation was evaluated qualitatively by a neurosurgeon and a neuroradiologist and by reviewing the prospective radiology reports. Additionally, ventricular volume changes were estimated using the frontal occipital horn ratio (FOHR). ${ }^{24,28}$ The FOHR is an average of the maximum lateral width of the frontal and occipital horns divided by the maximal lateral diameter of the cranium. Normal FOHR is approximately 0.37 and is independent of age. ${ }^{24}$ Whenever possible, FOHR indices were obtained for both "clinically baseline" imaging and preoperative "shunt failure" imaging. 
TABLE 1. Imaging classification of local catheter environment

\begin{tabular}{cc}
\hline \multicolumn{1}{c}{ Classification } & \multicolumn{1}{c}{ Definition } \\
\hline $\begin{array}{c}\text { Completely free } \\
\text { (class 1) }\end{array}$ & $\begin{array}{c}\text { CSF surrounds drainage holes of catheter tip } \\
\text { without any ventricular wall contact }\end{array}$ \\
\hline $\begin{array}{c}\text { Partial wall contact } \\
\text { (class 2) }\end{array}$ & $\begin{array}{c}\text { Drainage holes of catheter tip are in partial } \\
\text { contact with ventricular wall }\end{array}$ \\
\hline $\begin{array}{c}\text { Surrounded by tissue } \\
\text { (class 3) }\end{array}$ & $\begin{array}{c}\text { Ventricular wall and/or brain parenchyma sur- } \\
\text { rounds the proximal catheter tip with little or } \\
\text { no intervening CSF }\end{array}$ \\
\hline
\end{tabular}

Similar to previously published grading systems, 22,23 the local environment around ventricular catheter tips was assessed on brain CT or MRI scans.

\section{Results}

\section{Ependymal Bands Observed in Endoscopic Shunt Explorations}

Ependymal bands were commonly observed in endoscopic shunt explorations. A comprehensive review of all shunt procedures performed by the senior author between 2008 and 2015 identified 639 operations on ventricular shunts, among which 373 (58\%) were performed with endoscopic guidance. These included 79 operations for firsttime shunt placement, and 294 for revision, removal, and replacement (e.g., after infection), and primary or secondary ETV in the setting of an existing shunt. Among the 294 endoscopic procedures, 83 showed distinctive findings consisting of uniform protrusions of ventricular wall tissue organized in 1-cm-long rows corresponding to the rows of orifices along the catheter tip (Fig. 1).

Most ependymal bands were observed in patients whose primary diagnosis was proximal catheter obstruction (72/83 cases, $87 \%$; Table 2). However, bands were also noted in patients undergoing surgery for other, primarily nonmechanical shunt malfunctions, including treatment of shunt infection (4 cases), reconnection of a shunt after delayed ETV failure (1 case), or elective ETV ( 2 cases) in the setting of a functional shunt to achieve shunt independence (Table 2). Eighty-six percent of operative interventions for mechanical shunt failure were performed urgently (i.e., within 24-48 hours of presentation), and $14 \%$ were performed nonurgently in patients presenting with chronic symptoms.

\section{Ependymal Bands and Catheter Orifice Occlusion}

Ependymal bands lined up against the catheter orifices and occluded them partially or completely. In all cases, endoscopic exploration revealed regularly spaced, wellcircumscribed ependymal tissues protruding from the ventricular surface and arranged with direct correspondence to the pattern of drainage orifices in the catheter (Fig. 1). Most protrusions (56 cases, 67\%) were identified using a 1-mm flexible intracatheter endoscope during replacement of the proximal catheter (Fig. 1A and B). Others were observed using a $2.7-\mathrm{mm}$ rigid endoscope placed along the catheter track, or via a separate track for ETV (Fig. 1C-H).

Intraoperatively, we noted patency of virtually all valves and distal catheters, and either partial or complete occlusion of the catheter tip orifices. Specifically,
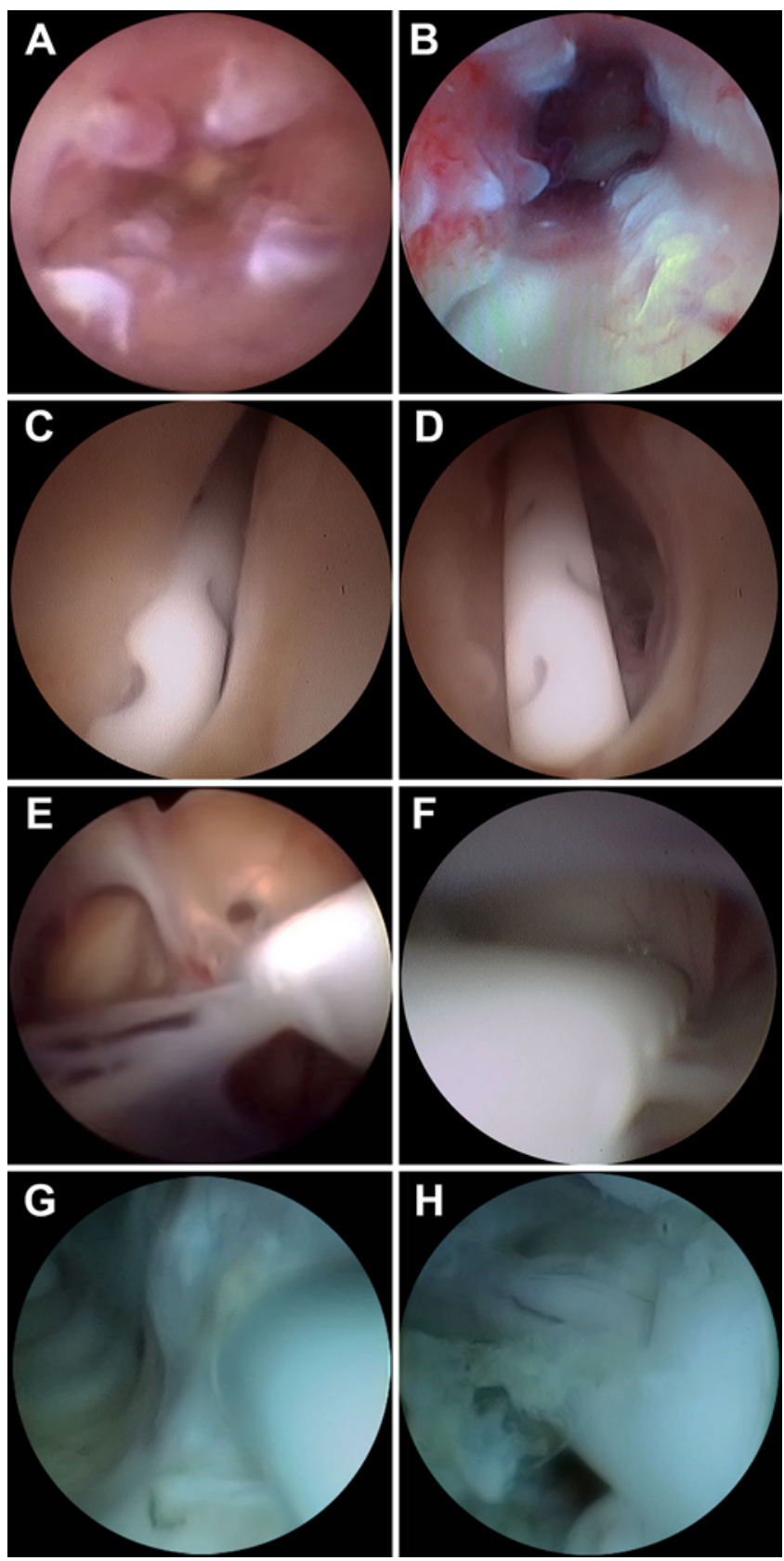

FIG. 1. A and B: Ependymal bands. Endoscopic images were obtained after removing the obstructed ventricular catheters, revealing 4 rows of well-organized ventricular wall tissue protrusions corresponding to the location of the orifices of the explanted catheter. $\mathbf{C}$ and D: Mild ependymal bands reversibly occlude the catheter (Video 1). These images were obtained after introducing the endoscope along the tract of the ventricular catheter revealing ventricular wall tissue penetrating the catheter orifices. When the catheter is allowed to drain freely $(C)$, the ventricle collapses around the catheter and the bands penetrate the orifices. When the catheter is manually occluded in the setting of slow intermittent irrigation (D), the ventricle enlarges and bands surrounding the catheter tip pull away from the orifices, thus potentially reestablishing patency and indicating that CSF drainage drives band formation (Videos 1 and 2). E and F: Moderate ependymal bands occlude and adhere to some of the orifices with or without complete obstruction. These images were obtained from two different patients in which the endoscope was introduced along the catheter tract without removing the adherent catheter. FIG. 1. (continued) $\rightarrow$ 
FIG. 1. Ependymal bands are large and extend into the catheter orifices, tethering the catheter to the ventricular wall. Moderate bands do not occlude all the orifices, which may or may not lead to a complete catheter obstruction. $\mathbf{G}$ and $\mathbf{H}$ : Severe ependymal bands with extensive tissue adhesions around the ventricular catheter tip and intraluminal debris. In these images, the endoscope was again introduced along the catheter tract without removing the adherent catheter. Image $\mathrm{G}$ shows extensive tissue adhesions requiring electrocautery to release them. Image $\mathrm{H}$ shows large ependymal wall protrusions plugging the catheter orifices. In this case the catheter was also fully encapsulated in tissue as it traversed the septum pellucidum.

spontaneous CSF flow from the ventricular catheter was assessed in 57 of the 72 mechanical shunt obstructions. Among these, good CSF flow was observed in 19 cases (33\%), slow or minimal flow in 23 cases (40\%), and no flow in 15 cases (26\%; Table 3 ). As previously shown, poor or absent flow on shunt tap is highly predictive of obstruction of the proximal catheter, with a positive predictive value of $93 \% .{ }^{33}$ Data from both shunt tap (not shown) and intraoperative CSF flow analysis were available from 49 cases $(68 \%)$. Forty one $(84 \%)$ of these showed good agreement, and only $8(16 \%)$ demonstrated contradictory findings. Inconsistencies may be attributed to temporal delay in data collection and/or the dynamic nature of CSF flow (Table 3).

\section{Ependymal Band Morphology and Size}

Ependymal bands demonstrate discrete morphologies or severity, which appear to correlate with catheter age. Twenty-eight cases with endoscopic video footage were available for review, demonstrating ependymal bands of various morphologies and sizes. Half of the media were obtained from the 1-mm intracatheter endoscope, and the other half from the 2.7-mm rigid glass rod endoscope. Bands were classified as mild, moderate, and severe based on endoscopic appearance. Mild bands were noted in 18 of the 28 cases. These were small tissue protrusions not accompanied by adhesions to the catheter (Fig. 1A-D), and accordingly were removed with gentle traction. Extracatheter endoscopy in 3 mild band cases showed that orifice occlusion by ventricular tissue can be successfully reversed by manually occluding the catheter to stop drainage. This leads to transient ventricular expansion and separation of the ependymal bands from the catheter (Video 1).

VIDEO 1. Clip showing an intraventricular endoscopic exploration with low-flow saline irrigation after ventricular catheter removal. Mild bands consist of solid mounds of tissue protruding into the ventricle along the site of the previous ventricular catheter. Bands have formed a uniform row of tissue protrusions along the ventricular walls that may intermittently occlude the catheter orifices. Moderate bands consist of bands of ventricular tissues irreversibly obstructing numerous catheter orifices, although several may remain patent. Severe ependymal bands are severely adherent ventricular tissues along the catheter surface and orifices. These tissues may break off and irreversibly occlude the catheter lumen. Note the tissue protrusions deeply enveloping the catheter side ports. Copyright Bermans J. Iskandar. Published with permission. Click here to view.

The median catheter age in patients with mild bands $(n=$
TABLE 2. Endoscopic shunt surgery indication in patients with ependymal bands

\begin{tabular}{cc}
\hline Endoscopic Shunt Surgery Indications/Findings & No. (\%) \\
\hline Mechanical shunt malfunctions & $76(92)$ \\
\hline Ventricular catheter obstruction & $72(87)$ \\
\hline Shunt disconnection & $3(4)$ \\
\hline Valve obstruction & $1(1)$ \\
\hline Nonmechanical malfunctions & $7(8)$ \\
\hline Shunt removal, replacement, or reconnection & $5(6)$ \\
\hline Elective secondary ETV & $2(2)$ \\
\hline
\end{tabular}

The majority of shunt revisions performed in patients with ependymal bands were for catheter obstruction (72/83). However, ependymal bands were found in a small number of patients with patent shunt systems who underwent surgery for other indications.

18) was 3 months (range 3 days to 9.2 years). Most cases with mild bands presented urgently with symptomatic catheter obstructions; however, 3 patients underwent surgery for nonobstructive infectious shunt complications.

Moderate and severe ependymal bands were noted in 10 of 28 cases; these demonstrated large tissue protrusions irreversibly tethered to the catheter (Fig. 1E-H). Bands of moderate severity $(n=4$, Fig. $1 \mathrm{E}$ and $\mathrm{F})$ consisted of partially occlusive tissue adhesions with 1 or more bands of tissue extending into the drainage orifices, whereas severe bands ( $\mathrm{n}=6$, Fig. $1 \mathrm{G}$ and $\mathrm{H}$ ) demonstrated fully occlusive intra- and extracatheter tissue adhesions with significant intracatheter debris. Intraoperative observation suggested that intracatheter debris is a result of spontaneous fragmentation of ependymal bands. In some cases, however, the debris appeared to have resulted from mechanical retrieval of the tethered catheter with or without stylet coagulation. The median catheter age among moderate and severe bands $(\mathrm{n}=10)$ was 7.25 years (range 4 months to more than 20 years). Although most patients $(n=8)$ with advanced band morphology presented urgently with obstructions of the ventricular catheter, 2 presented nonurgently with progressive headaches and ventricular dilation: 1 had a shunt disconnection and the other a failed ETV. Both cases demonstrated ependymal bands of moderate severity. It is unclear whether band morphology correlates with severity of obstruction and/or patient presentation. Our limited data set does not allow further analysis, nor does it allow correlation of band severity with specific symptomatic states.

\section{Ependymal Bands and Catheter Adherence}

Ependymal bands may adhere to the catheter, and catheter adherence correlates with long-term shunting. Our endoscopic observations strongly suggest that ependymal bands are responsible for the ventricle-catheter adherence previously described. Of 74 shunt procedures reviewed (i.e., excluding ETV and surgery for shunt infection), 58 $(78 \%)$ had documentation of catheter adherence or nonadherence in the operative report. Of these, 38 (66\%) reported catheter adherence to brain tissue, with the remaining $20(34 \%)$ reporting nonadherent catheters. 
TABLE 3. Assessment of CSF flow among obstructive shunt malfunctions

\begin{tabular}{lcc}
\hline CSF Flow & Shunt Tap & Assessment in OR \\
\hline Good & $10(17 \%)$ & $19(33 \%)$ \\
\hline Slow/minimal & $12(21 \%)$ & $23(40 \%)$ \\
\hline Absent flow & $36(62 \%)$ & $15(26 \%)$ \\
\hline Total & $58(81 \%)$ & $57(79 \%)$ \\
\hline
\end{tabular}

$\mathrm{OR}=$ operating room.

CSF flow was determined either by performing a shunt tap as previously described ${ }^{21}$ or through direct testing at surgery after disconnecting the ventricular catheter from the valve. Flow findings are shown for cases with proven ventricular catheter obstruction associated with ependymal bands (n = 72). Most patients with shunt obstruction associated with ependymal bands showed poor or absent CSF flow on shunt tap (83\%) or intraoperative exploration $(66 \%)$. Note that the populations that underwent shunt tap $(n=58)$ versus intraoperative flow assessment $(n=57)$ were not identical. Of the 49 cases that had both shunt tap and intraoperative flow assessment, 41 (84\%) showed good agreement.

Catheter age was determined in 80 of 83 cases (96\%). The median catheter age was 14.5 months (range 1 day to more than 20 years). In obstructive cases in which adherence was assessed (70 catheters), the median age of adherent $(n=36)$ and nonadherent $(n=20)$ catheters was 19 months (range 31 days to 14 years) and 3 months (range 1 day to 9 years), respectively (Fig. 2). While the data indicate that catheter adherence occurs more commonly with older catheters ( $p=0.02$, Mann-Whitney U-test), inconsistencies exist in that some catheters become adherent as early as 1 month after insertion, while others remain free of adhesions for many years after implantation.

\section{Ventricle Size and Ependymal Bands}

Ventricles associated with ependymal bands are uniformly small when the shunt was functional, but can enlarge during a shunt malfunction. For ventricular tissue to grow into catheter orifices, the ventricles must approximate the shunt tubing. To determine whether ependymal band formation is exclusively associated with small ventricles, we examined ventricle size in our study population both at baseline ("clinical baseline" scans) and at time of shunt malfunction prior to surgical exploration ("shunt malfunction" scans). In addition, an imaging classification system was used to characterize the catheter tip environment (Table 1).

\section{"Clinical Baseline" Imaging}

The shunt was considered functional when either 1) the patient was asymptomatic or 2) the patient had transient symptoms associated with a normal shunt tap and small or unchanged ventricles. "Clinical baseline" scans were available in $61(73 \%)$ of the ependymal band cases described in this report, and include a high proportion of slit-like ventricles with a median FOHR of $0.33 \pm 0.04$ and a range of $0.17-0.43$. Among this population, 56 cases (92\%) had catheters that were surrounded by brain tissue with little or no intervening CSF (class 3), and 8\% had partial contact with the ventricular wall (class 2). All clinical baseline scans of patients with ependymal bands were found to

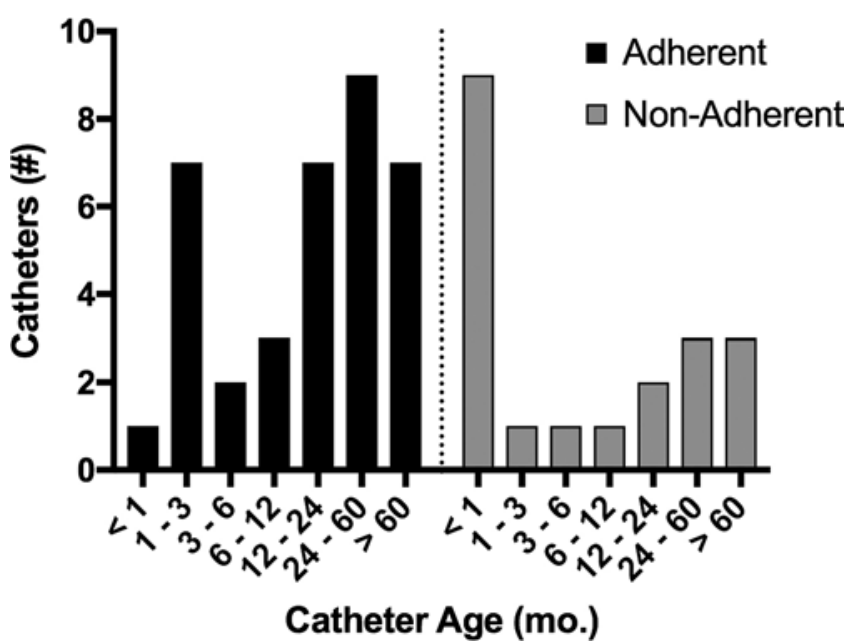

FIG. 2. Catheter age (months) at time of malfunction. Duration of catheter implantation among adherent (black) and nonadherent (gray) catheters is shown. The data indicate that the older the catheter, the more likely it is to be adherent, and that most nonadherent catheters were implanted within a month of shunt revision surgery $(n=36$ adherent catheters, $n=20$ nonadherent catheters). Note: If the catheter age was exactly the same as one of the numbers in a range (such as 3 months), it was counted in the range that begins with that value (i.e., in the 3- to 6 -month range on the graph).

have catheter tips that were not completely surrounded by CSF (class 2 and 3), indicating that the presence of bands is strongly associated with contiguity of the catheter to one or more ependymal walls or septum pellucidum (Table 4).

\section{"Shunt Malfunction" Imaging}

CT and/or MRI scans obtained at the time of shunt malfunction were available in 63 cases $(76 \%)$. Most of these scans $(75 \%)$ were acquired within 5 days of surgery, although older imaging was used for some patients pre-

TABLE 4. Proximal catheter tip environment on imaging during shunt malfunction and at baseline

\begin{tabular}{|c|c|c|}
\hline \multirow[b]{2}{*}{$\begin{array}{c}\text { Proximal Catheter Tip } \\
\text { Environment }\end{array}$} & \multicolumn{2}{|c|}{ Imaging (\%) } \\
\hline & $\begin{array}{l}\text { At Shunt } \\
\text { Malfunction }\end{array}$ & $\begin{array}{c}\text { When Clinically } \\
\text { Stable }\end{array}$ \\
\hline Completely free (class 1) & $1(1)$ & $0(0)$ \\
\hline Partial wall contact (class 2) & $13(21)$ & $5(8)$ \\
\hline Surrounded by brain (class 3 ) & $49(78)$ & $56(92)$ \\
\hline Total & $63(76)$ & $61(73)$ \\
\hline
\end{tabular}

CT and MRI scans obtained preoperatively during shunt malfunction $(n=63)$ and when the shunt was considered functional $(n=61)$ were reviewed for assessment of local catheter tip environment, as described in Table 1. The results indicate that the vast majority of patients with ependymal bands who suffer a shunt obstruction have evidence of contact between the tip of the ventricular catheter and one or both ventricular walls. Complete enclosure of the catheter tip (class 3 ) is especially common ( $92 \%$ ) when the patient is clinically stable and the ventricles are collapsed. However, it is notable that while the ventricles often expand due to shunt malfunction, the part of the ventricle surrounding the catheter tip (usually the frontal horn) may not, showing class 3 tip environment in $78 \%$ of cases. 
viously recognized to have ventricles that do not dilate during malfunction (median 1 day preoperatively, range 0-84 days). According to the radiology reports, proximal obstructions in patients with and without evidence of ependymal bands showed no ventricular dilation in $51 \%$ and $41 \%$ of cases, respectively. Additionally, there were 4 band cases $(6 \%)$ with no ventricular dilation in which there were other signs of shunt malfunction, including an expanding arachnoid cyst, pseudomeningocele, spinal syrinx, and subcutaneous CSF collection along the shunt tract. Detailed imaging analysis by a neuroradiology/neurosurgery team showed a median FOHR of $0.35 \pm 0.04$ with a range of $0.28-0.43$. Among malfunctioning shunts, $78 \%$ of catheter tips were surrounded by brain tissue (class 3), $21 \%$ had partial contact with ventricular wall tissue (class 2), and there was only 1 instance of a catheter tip surrounded by CSF (class 1). The latter case occurred in a patient who had undergone a distant ETV operation and presented for shunt reconnection. Taken together, these data indicate that the ventricles of patients with ependymal bands may enlarge in the setting of proximal shunt obstruction. However, patients documented to have ependymal bands are less likely to show ventricular dilation than those with no documented bands.

\section{Ependymal Bands Secondary to CSF Drainage}

Ependymal bands appear to form secondary to active $\mathrm{CSF}$ drainage. At our center, constant saline irrigation and concomitant external drainage routinely accompany ventricular endoscopy, especially when using rigid glass rod endoscopes. When the endoscope is introduced along the catheter tract, the existing ventricular catheter is routinely disconnected from the valve to allow drainage of the irrigating fluid. In 3 select cases, CSF drainage was experimentally blocked via manual compression of the catheter during endoscopic inspection of the ependymal bands. In all 3 cases, during active irrigation and drainage, ventricular tissue was found to actively migrate into the catheter orifices. Conversely, when the catheter was occluded to prevent external drainage, ependymal tissue was observed to separate from the catheter orifices accompanied by at least mild ventricular dilation (Fig. 1C and D, Video 1). One case provides additional insight into band formation demonstrating transient ependymal band formation with active drainage, and band resolution (flattening of ependyma) when drainage is interrupted (Video 2).

VIDEO 2. Segment 1: Chronically formed ependymal bands. Clip showing an intraventricular endoscopic exploration with low-flow saline irrigation with the ventricular catheter in place. When the ventricular catheter is disconnected from the valve and allowed to drain freely, the ventricle gets smaller and well-formed ependymal bands that consist of organized mounds of tissue obstruct the catheter orifices. However, when the catheter is manually occluded, the ventricle expands and the ependymal bands separate from the catheter, reversing the obstruction, and indicating that obstructions are driven by CSF drainage. Segment 2: Acutely formed ependymal bands. When the ventricular catheter is disconnected from the valve and allowed to drain freely, the ventricle gets smaller and ependymal tissue obstructs the catheter orifices. As in segment 1, when the catheter is manually occluded, the ventricle expands and the ependymal bands separate from the catheter, reversing the obstruction. Unlike segment 1, however, the ependymal bands have yet to form organized mounds of tissue. Instead, when the catheter is manu- ally occluded, the ependyma flattens and the bands resolve. We presume segment 2 represents an early stage in ependymal band formation, whereas segment 1 shows ependymal tissue that formed and stiffened over time. Copyright Bermans J. Iskandar. Published with permission. Click here to view.

In other situations, bands were solid and fixed regardless of drainage pattern or intraventricular irrigation. These observations suggest that the process of suction from active CSF drainage first leads to the formation of the ependymal bands, then continued long-term suction (gravitational shunt drainage) creates progressive band stiffening and maturation, presumably from inflammation, gliosis, cellular damage, and other changes.

\section{Nonependymal Drainage-Driven Tissue In-Growth}

Drainage-driven tissue in-growth is not limited to ependyma, but may also include choroid plexus and vascular tissues. Our series includes 6 cases (7\%) in which obstruction of the catheter was caused at least in part by choroid plexus in-growth. These data indicate that ventricular protrusions are not limited to ependyma, but they may form from any tissue juxtaposed to the catheter. Importantly, during endoscopic exploration in the presence of a ventricular catheter, loose vessels are often drawn into a catheter, but only when the catheter is open to drain, and not when the catheter is experimentally occluded. This again suggests that the mere proximity of the catheter is unlikely to draw tissue in. Rather, tissue is pulled in through the process of drainage, and in particular overdrainage through gravitational forces.

\section{Ependymal Band Epidemiology and Correlations}

Patients with shunt-related ependymal bands follow typical epidemiology, and ependymal band formation shows no obvious correlation with age, hydrocephalus etiology, or valve type. Fifty patients ( 32 children, 18 adults) underwent 83 endoscopic shunt surgeries with ependymal band findings. The median age at the time of surgery was 13 years, with a range from 2 to 48 years. The predominant etiologies of hydrocephalus were myelomeningocele, intraventricular hemorrhage (IVH) of prematurity, congenital etiologies, tumor, infection, and others (Table 5). Most patients had their initial shunt placed in infancy (72\%). Ten patients (20\%) had their original shunt placed before age 10, and in $4(8 \%)$ the shunts were placed later in life. The median duration of shunting (i.e., length of time from first-time shunt placement to first revision surgery with documented endoscopic findings) was 10 years, with a range of 2 months to 48 years. Eighty-one percent of shunts were parietooccipital, and 19\% were frontal, reflecting the primary author's practice pattern. All but 1 patient had at least 1 shunt revision surgery prior to the observation of ependymal bands. Valve types were reflective of national practice patterns, ${ }^{21}$ and include programmable valves (20\%), simple differential pressure valves (52\%), differential pressure valves with integrated antisiphon device (12\%), flow-regulated valves $(8 \%)$, and unknown (7\%). Although the results do not demonstrate an obvious association between ependymal bands and valve type, patient age, or hydrocephalus etiology, the small sample size in each group precludes detailed statistical analyses. 


\section{Discussion}

\section{Shunt Overdrainage, Ependymal Band Formation, and Proximal Shunt Obstruction}

Proximal catheter malfunction remains the most challenging problem afflicting ventricular shunts. Based on our endoscopic observations, we propose that chronic shunt overdrainage may be an important, if not predominant, factor leading to such malfunctions. Specifically, our endoscopic data demonstrate that 1) CSF shunting leads to the development of ventricular tissue protrusions or bands that line up along the catheter orifices to occlude them partially or completely; 2) ependymal bands, whether mild, moderate, or severe, may acutely occlude the ventricular catheter, leading to elevated intracranial pressure requiring urgent shunt revision; 3 ) the severity of the ependymal bands correlates with the length of time that the catheter has been implanted; and 4) the bands seem to form during active CSF drainage through the catheter. Decidedly, despite similar rates of infection and hemorrhagic complications, tissue obstruction of ventricular devices such as Rickham reservoirs and/or subgaleal shunts, which do not involve gravitational drainage, has not been reported. ${ }^{39}$ Overdrainage is by no means a novel concept, as neurosurgeons have often suspected that shunts may be doing "too much," and often have advocated for higher-resistance valve mechanisms (e.g., flow-regulated valves such as the Orbis-Sigma valve system and antisiphon devices). . $^{10,30,35}$

Although our retrospective data set is limited, we suspect that ependymal bands may be present in most ventricular catheter obstructions. Other pediatric neurosurgeons have admittedly observed, though rarely reported, ${ }^{23,37}$ similar ventricular wall abnormalities during routine shunt endoscopy. Interestingly, even in patients treated for nonobstructive shunt pathology, endoscopic evidence shows that those with functioning shunts may harbor ependymal bands at various stages of development. Because adequate shunt function may be maintained with patency of only a portion of the catheter orifices, patients with intermittently or partially obstructing ependymal bands may remain asymptomatic.

\section{Ependymal Band Formation, Reversibility, and Severity}

Early Bands: Reversible and Intermittently Symptomatic

Ependymal bands appear to develop as tissue along the ependymal surface (presumably ependymal and subependymal tissue) is drawn into the catheter orifices with CSF drainage. The shunt drainage process appears to be the primary mechanism of ependymal band formation. Protrusions form when ventricular tissues are drawn into a draining catheter (Video 2). Initially, this process may be reversible, with temporary CSF obstruction leading to transient intracranial pressure elevation with or without symptoms; this results in small or large ventricular expansion, which in turn leads to retraction of the bands away from the catheter (Video 2). After resolution of the obstruction, this process may repeat itself (Fig. 3A). Although this cyclical process is akin to the mechanism thought to cause slit ventricle syndrome (estimated in only $10 \%-12 \%$ of patients), ${ }^{27}$ we propose that it occurs more commonly, perhaps in most patients with shunted hydrocephalus and
TABLE 5. Patient epidemiology

\begin{tabular}{cc}
\hline \multicolumn{1}{c}{ Variable } & No. $(\%)$ \\
\hline Patient age (yrs) & $15(30)$ \\
\hline$<10$ & $22(44)$ \\
\hline $10-20$ & $13(26)$ \\
\hline$>20$ & $1(2)$ \\
\hline Duration of shunting (yrs) & $8(16)$ \\
\hline$<1$ & $14(28)$ \\
\hline 1 to $<5$ & $27(54)$ \\
\hline $5-10$ & $15(30)$ \\
\hline$>10$ & $11(22)$ \\
\hline Etiology of hydrocephalus & $6(12)$ \\
\hline Myelomeningocele & $3(6)$ \\
\hline IVH (prematurity) & $1(2)$ \\
\hline Congenital & $1(2)$ \\
\hline Tumor & $1(2)$ \\
\hline Subarachnoid hemorrhage & $5(10)$ \\
\hline IVH (non-prematurity) & $6(12)$ \\
\hline Postinfectious & \\
\hline Other & \\
\hline Unknown & \\
\hline
\end{tabular}

Fifty patients underwent 83 operative interventions. The table shows patient age and duration of shunting at first documentation of ependymal bands, and etiology of the hydrocephalus. Other etiologies included Chiari malformation type 1 , head injury, and obstructive arachnoid cysts.

small ventricles. And while some of these patients remain asymptomatic, others develop temporary or permanent obstructions. Importantly, despite their mild appearance, early ependymal bands may generate clinically significant obstructions requiring emergency shunt revision. It is unclear why some patients are more susceptible to symptomatic obstruction than others. We suspect this may be a consequence of ventricular dynamics, in that patients with more compliant ventricles may be able to tolerate numerous cycles of transient obstruction, whereas those with less compliant ventricles present with acute shunt malfunction. In fact, decreased ventricular compliance may itself result from, at least in part, chronic overshunting.

\section{Chronic Bands: Fixed Protrusions With Inflammatory Changes}

With continued shunting, the bands seem to become fixed, forming rigid mounds of tissue, likely from a combination of anatomical distortion of ependymal and subependymal tissue formed by suction, and a secondary inflammatory process. Indeed, chronic reactive and inflammatory changes of tissue lodged in explanted catheter tips have been documented by a range of studies., ${ }^{4,12,13,36}$ Our retrospective data set is incapable of determining the exact timeline, although it appears this process may start as early as 2 months after shunt placement.

\section{Chronic Bands: Adherence to Surrounding Tissue}

We have also observed that with chronic shunting, ventricular catheters often become adherent to surrounding brain tissue. Endoscopy shows that extensive tissue may 


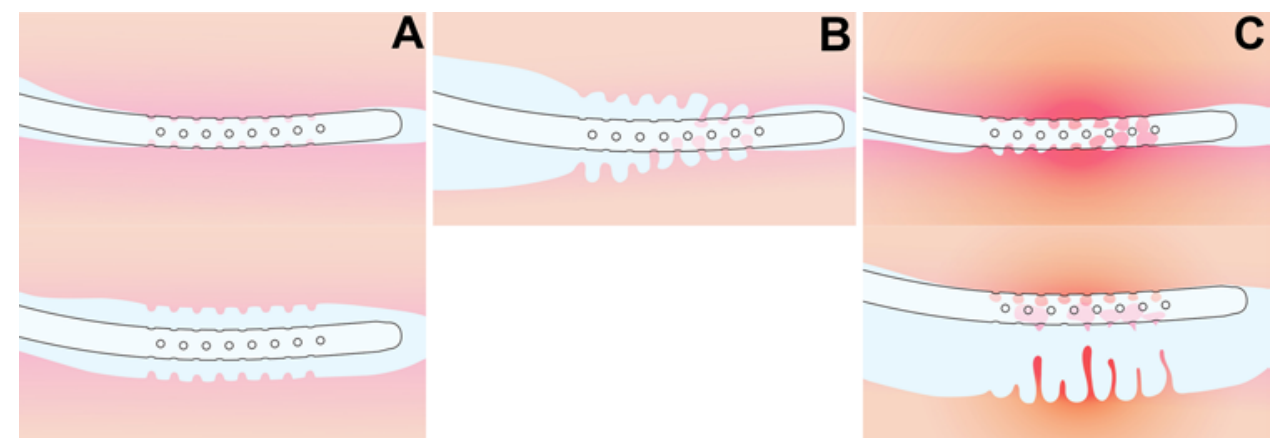

FIG. 3. A: Early or mild ependymal bands. At an early stage of ependymal band development, the ventricular wall is capable of dynamically obstructing the catheter. In the upper image, the ventricle has collapsed and bands have occluded the catheter orifices. In the lower image, the ventricle has dilated, thus relieving the obstruction. Dynamic obstruction of the catheter orifices may produce symptoms similar to slit ventricle syndrome or may remain asymptomatic (Videos 1 and 2). B: Advanced or moderate ependymal bands. This schematic illustrates tethering of ependymal bands to some but not all the orifices of the ventricular catheter. Depending on which orifices are occluded, the catheter could remain patent, be partially obstructed, or suffer from a full obstruction. C: Severe ependymal bands. This schematic illustrates advanced ventricular protrusions with complete occlusion of the catheter, usually producing an acute shunt malfunction. Depending on the compliance of the ventricular system, some of these occlusions may lead to ventricular dilation (lower image), which may or may not relieve the obstruction and symptoms. In others, the ventricles do not change in size, or change minimally, and the obstruction persists (upper image). In such advanced cases, the ependymal tissue may break off and lodge in the catheter lumen, especially when the ventricles dilate. Such debris can also be created when the catheter is released from adherent bands during shunt revision.

surround the catheter, which can result in significant adhesions to both the intraluminal and external catheter surfaces. A subset of patients with such adhesions may develop a complete catheter obstruction requiring urgent surgery, while others suffer from partial catheter obstructions accompanied by preservation of some CSF flow (Fig. 3B). Accordingly, many partial obstructions related to ependymal bands do not require urgent surgery. In the present series, ependymal bands were present in 7 surgical shunt explorations done for nonobstructive reasons. Yet, such partial obstructions may contribute to clinical symptoms, such as intermittent headaches.

\section{Chronic Bands: Intraluminal Debris}

As ependymal bands become further integrated into the catheter, they may spontaneously break off to lodge in the catheter lumen and often provoke an acute catheter obstruction. Additionally, detached tissue plugs may migrate to the valve, as seen in 1 case in this series. At surgery, a large plug of tissue is often encountered within the lumen of the catheter. When gentle coagulation through a stylet is used to remove these catheters, the original orderly ventricular protrusions may be damaged, resulting in an irregular and damaged ventricular surface.

\section{Ventricular Size, Ventricular Tip Environment, and Proximal Shunt Obstruction}

Although few patients are diagnosed with slit ventricle syndrome,, 529 it is apparent that many patients with shunts develop abnormally small ventricles, a process that appears to be independent of valve mechanism or catheter position. ${ }^{18,40,42}$ While the process of ventricular collapse is difficult to predict for individual patients, it appears that significant decline in volume may occur within a year of shunt placement. ${ }^{40,42}$ Furthermore, ventricular catheter tip environment has been shown to be predictive of shunt obstruction ${ }^{4}$ in that catheter tips completely surrounded by CSF have a near $80 \%$ reduction in risk of obstruction compared to catheters in contact with surrounding brain or ventricular tissue. ${ }^{40}$ Recent reports suggest that patients with greater reductions in ventricular volume tend to have a higher probability of shunt malfunction. ${ }^{18,25}$

The endoscopic findings presented here provide further evidence of a link between imaging, catheter environment, and shunt obstruction. Specifically, we demonstrate that collapse of the ventricles and juxtaposition of the catheter surface to the ventricular wall correlate with partial or complete catheter obstruction. Review of brain imaging studies obtained in patients with ependymal bands reveals that when the shunt is patent, $93 \%$ show ventricular collapse, and the remaining 7\% show partial contact of the catheter tip with the ventricular wall. Yet, during shunt malfunction, nearly half will dilate their ventricles. Ventricular dilation implies that the combination of rising intraventricular pressure and sufficient ventricular wall compliance allows for stretching or breaking of tissue adhesions on one or more sides of the catheter (Fig. 3C, lower). Conversely, when compliance is poor or adhesions particularly robust, the ventricle does not expand, and the catheter is found firmly invested in brain tissue (Fig. 3C, upper).

Notably, a recent, large, multicenter prospective cohort study confirmed earlier observations from the literature that shunts placed before 6 months of age are associated with greater failure rates. ${ }^{32}$ Given our endoscopic findings, it is intriguing to consider the consequences of CSF overshunting on the immature brain and ventricles and in light of a flexible skull susceptible to craniocerebral disproportion. ${ }^{34}$ Such biophysical properties may place younger patients at higher risk of ventricular catheter obstruction. 


\section{Choroid Plexus and Blood Vessel Migration}

Choroid plexus and blood vessels may migrate into catheter orifices presumably through a similar overdrainage mechanism. Despite growing evidence to the contrary, ${ }^{4,36,37}$ surgeons often attribute obstructive shunt failure to choroid plexus migration into the catheter, ${ }^{21}$ an attribution that appears to have been popularized by several early histological studies.7,11 The present study further refutes the notion that the choroid plexus is responsible for most ventricular obstructions. In our series, the choroid plexus was noted to obstruct the catheter in only 6 cases $(7 \%)$. But even in these cases, endoscopy showed that choroid plexus migration into the shunt catheter is often related to siphoning rather than spontaneous migration of tissue.

\section{Study Limitations}

This small, retrospective case series has several limitations. First, our data set is weighted to the latter half of our study period. Ependymal bands were first observed incidentally during routine endoscopic shunt surgery. Many of these observations were limited to short descriptions in the operative notes, often without recorded footage. However, as the senior author began to appreciate the importance and prevalence of these findings, more thorough endoscopic explorations were documented in later years. Thus, despite a stable number of shunt procedures per year throughout the study period, nearly $70 \%$ of ependymal bands were observed in the second half of the study period (2012-2015). This suggests that although it is difficult to assess the true prevalence of ependymal bands, they are more common than originally believed, and may be ubiquitous. Likewise, shunt malfunction workups were clinically driven. Thus, baseline imaging, shunt taps, and flow findings are not available in all cases. Ideally, prospective investigations should be performed to further understand incidence, imaging, and CSF flow characteristics of proximal shunt obstructions associated with ependymal bands.

Second, the patient population studied here includes adults with chronic shunts, which means that it is, on average, older than that in other series. . $^{12,19,32,41}$ This may contribute to a selection bias for patients more likely to have small ventricles, which supports the importance of future age-matched prospective series. Furthermore, although ependymal band formation appears independent of hydrocephalus etiology and valve type, both of which closely parallel national trends, ${ }^{8,19,32,41}$ future large series may yield subset analyses with correlations to ependymal bands that are not evident in the present study.

Third, the preferred shunt placement approach at our center is parietooccipital rather than frontal. In this study, $81 \%$ and $19 \%$ of endoscopic findings reported were from catheters placed from parietooccipital and frontal approaches, respectively. This reflects our practice pattern. While a recent multicenter cohort analysis suggests that frontally placed ventricular catheters are associated with increased revision-free survival, ${ }^{41}$ the literature on the topic remains controversial. ${ }^{2,3}$ Specifically comparing frontal versus parietooccipital approach catheters is beyond the scope of this study. However, in future work, it will be important to examine whether catheter position affects the extent of overdrainage as well as the development and/or characteristics of ependymal bands.

Fourth, although we propose that overdrainage is a primary mechanism leading to the development of the ependymal bands and subsequent proximal catheter obstruction, these data do not rule out other contributing etiologies. In particular, there is growing evidence that reactive and inflammatory processes may be involved in ventricular catheter obstructions..$^{4,12-15}$ It is unknown if or how these processes interact with the overdrainage mechanism described here. One possibility that we favor is that the inflammatory changes may be due to overdrainagedriven ependymal injury. Accordingly, a prospective trial should include an effort to catalog endoscopic, histological, and clinical data for patients with proximal ventricular catheter obstructions.

Finally, a survey of experienced North American pediatric neurosurgeons showed that most surgeons do not believe overdrainage is a common problem in their practice, considering that there is a paucity of patients with overt overdrainage symptoms and signs such as postural headaches and subdural hematomas. ${ }^{21}$ Demonstrating that reducing shunt overdrainage decreases shunt malfunction rates would lend conclusive evidence to the overdrainage hypothesis of shunt obstruction.

\section{Conclusions}

Hydrocephalic patients with ventricular CSF shunts are susceptible to ventricular tissue protrusions (ependymal bands) that line up along the catheter orifices to occlude them partially or completely. Such obstructions may also be temporary and cyclical, reminiscent of slit ventricle syndrome. We propose that ependymal bands form secondary to chronic shunt siphoning and are a leading cause of proximal shunt obstruction. This supports recommendations that shunt overdrainage mechanisms should be taken into strong consideration in the design of shunt systems.

\section{Acknowledgments}

Funding was provided by the Theodore W. Batterman Family Foundation.

\section{References}

1. Acakpo-Satchivi L, Shannon CN, Tubbs RS, Wellons JC III, Blount JP, Iskandar BJ, et al: Death in shunted hydrocephalic children: a follow-up study. Childs Nerv Syst 24:197-201, 2008

2. Albright AL, Haines SJ, Taylor FH: Function of parietal and frontal shunts in childhood hydrocephalus. J Neurosurg 69:883-886, 1988

3. Bierbrauer KS, Storrs BB, McLone DG, Tomita T, Dauser R: A prospective, randomized study of shunt function and infections as a function of shunt placement. Pediatr Neurosurg 16:287-291, 1990-1991

4. Blegvad C, Skjolding AD, Broholm H, Laursen H, Juhler M: Pathophysiology of shunt dysfunction in shunt treated hydrocephalus. Acta Neurochir (Wien) 155:1763-1772, 2013

5. Browd SR, Gottfried ON, Ragel BT, Kestle JR: Failure of cerebrospinal fluid shunts: part II: overdrainage, loculation, and abdominal complications. Pediatr Neurol 34:171-176, 2006 
6. Browd SR, Ragel BT, Gottfried ON, Kestle JR: Failure of cerebrospinal fluid shunts: part I: obstruction and mechanical failure. Pediatr Neurol 34:83-92, 2006

7. Collins P, Hockley AD, Woollam DHM: Surface ultrastructure of tissues occluding ventricular catheters. J Neurosurg 48:609-613, 1978

8. Drake JM, Kestle JR, Milner R, Cinalli G, Boop F, Piatt J Jr, et al: Randomized trial of cerebrospinal fluid shunt valve design in pediatric hydrocephalus. Neurosurgery 43:294-305, 1998

9. Gmeiner M, Wagner H, Zacherl C, Polanski P, Auer C, van Ouwerkerk WJR, et al: Long-term mortality rates in pediatric hydrocephalus - a retrospective single-center study. Childs Nerv Syst 33:101-109, 2017

10. Gruber RW, Roehrig B: Prevention of ventricular catheter obstruction and slit ventricle syndrome by the prophylactic use of the Integra antisiphon device in shunt therapy for pediatric hypertensive hydrocephalus: a 25 -year follow-up study. J Neurosurg Pediatr 5:4-16, 2010

11. Hakim S: Observations on the physiopathology of the CSF pulse and prevention of ventricular catheter obstruction in valve shunts. Dev Med Child Neurol Suppl 20:42-48, 1969

12. Hanak BW, Ross EF, Harris CA, Browd SR, Shain W: Toward a better understanding of the cellular basis for cerebrospinal fluid shunt obstruction: report on the construction of a bank of explanted hydrocephalus devices. J Neurosurg Pediatr 18:213-223, 2016

13. Harris CA, McAllister JP II: What we should know about the cellular and tissue response causing catheter obstruction in the treatment of hydrocephalus. Neurosurgery 70:15891602,2012

14. Harris CA, Resau JH, Hudson EA, West RA, Moon C, Black $\mathrm{AD}$, et al: Effects of surface wettability, flow, and protein concentration on macrophage and astrocyte adhesion in an in vitro model of central nervous system catheter obstruction. $\mathbf{J}$ Biomed Mater Res A 97:433-440, 2011

15. Harris CA, Resau JH, Hudson EA, West RA, Moon C, McAllister JP II: Mechanical contributions to astrocyte adhesion using a novel in vitro model of catheter obstruction. Exp Neurol 222:204-210, 2010

16. Iskandar BJ, Sansone JM, Medow J, Rowley HA: The use of quick-brain magnetic resonance imaging in the evaluation of shunt-treated hydrocephalus. J Neurosurg 101 (2 Suppl):147-151, 2004

17. Iskandar BJ, Tubbs S, Mapstone TB, Grabb PA, Bartolucci AA, Oakes WJ: Death in shunted hydrocephalic children in the 1990s. Pediatr Neurosurg 28:173-176, 1998

18. Jain H, Natarajan K, Sgouros S: Influence of the shunt type in the difference in reduction of volume between the two lateral ventricles in shunted hydrocephalic children. Childs Nerv Syst 21:552-558, 2005

19. Kestle JR, Drake JM, Cochrane DD, Milner R, Walker ML, Abbott R III, et al: Lack of benefit of endoscopic ventriculoperitoneal shunt insertion: a multicenter randomized trial. J Neurosurg 98:284-290, 2003

20. Kestle J, Drake J, Milner R, Sainte-Rose C, Cinalli G, Boop F, et al: Long-term follow-up data from the Shunt Design Trial. Pediatr Neurosurg 33:230-236, 2000

21. Kraemer MR, Sandoval-Garcia C, Bragg T, Iskandar BJ: Shunt-dependent hydrocephalus: management style among members of the American Society of Pediatric Neurosurgeons. J Neurosurg Pediatr 20:216-224, 2017

22. Kulkarni AV, Riva-Cambrin J, Butler J, Browd SR, Drake JM, Holubkov R, et al: Outcomes of CSF shunting in children: comparison of Hydrocephalus Clinical Research Network cohort with historical controls: clinical article. J Neurosurg Pediatr 12:334-338, 2013

23. Nagata Y, Takeuchi K, Kato M, Osawa H, Watanabe T, Wakabayashi T: The "steppingstone" phenomenon: a new endoscopic finding in slit-ventricle syndrome. Childs Nerv Syst 32:2265-2268, 2016

24. O'Hayon BB, Drake JM, Ossip MG, Tuli S, Clarke M: Frontal and occipital horn ratio: a linear estimate of ventricular size for multiple imaging modalities in pediatric hydrocephalus. Pediatr Neurosurg 29:245-249, 1998

25. Patra DP, Bir SC, Maiti TK, Kalakoti P, Cuellar H, Guthikonda $\mathrm{B}$, et al: Role of radiological parameters in predicting overall shunt outcome after ventriculoperitoneal shunt insertion in pediatric patients with obstructive hydrocephalus. Neurosurg Focus 41(5):E4, 2016

26. Paulsen AH, Lundar T, Lindegaard KF: Pediatric hydrocephalus: 40-year outcomes in 128 hydrocephalic patients treated with shunts during childhood. Assessment of surgical outcome, work participation, and health-related quality of life. J Neurosurg Pediatr 16:633-641, 2015

27. Pudenz RH, Foltz EL: Hydrocephalus: overdrainage by ventricular shunts. A review and recommendations. Surg Neurol 35:200-212, 1991

28. Ragan DK, Cerqua J, Nash T, McKinstry RC, Shimony JS, Jones BV, et al: The accuracy of linear indices of ventricular volume in pediatric hydrocephalus: technical note. J Neurosurg Pediatr 15:547-551, 2015

29. Rekate HL: Shunt-related headaches: the slit ventricle syndromes. Childs Nerv Syst 24:423-430, 2008

30. Rekate HL: The slit ventricle syndrome: advances based on technology and understanding. Pediatr Neurosurg 40:259263,2004

31. Rekate HL, Kranz D: Headaches in patients with shunts. Semin Pediatr Neurol 16:27-30, 2009

32. Riva-Cambrin J, Kestle JR, Holubkov R, Butler J, Kulkarni $\mathrm{AV}$, Drake J, et al: Risk factors for shunt malfunction in pediatric hydrocephalus: a multicenter prospective cohort study. $\mathbf{J}$ Neurosurg Pediatr 17:382-390, 2016

33. Rocque BG, Lapsiwala S, Iskandar BJ: Ventricular shunt tap as a predictor of proximal shunt malfunction in children: a prospective study. J Neurosurg Pediatr 1:439-443, 2008

34. Ros B, Iglesias S, Martín Á, Carrasco A, Ibáñez G, Arráez MA: Shunt overdrainage syndrome: review of the literature. Neurosurg Rev [epub ahead of print], 2017

35. Sainte-Rose C, Piatt JH, Renier D, Pierre-Kahn A, Hirsch JF, Hoffman HJ, et al: Mechanical complications in shunts. Pediatr Neurosurg 17:2-9, 1991-1992

36. Sarkiss CA, Sarkar R, Yong W, Lazareff JA: Time dependent pattern of cellular characteristics causing ventriculoperitoneal shunt failure in children. Clin Neurol Neurosurg 127:30-32, 2014

37. Singh D, Saxena A, Jagetia A, Singh H, Tandon MS, Ganjoo P: Endoscopic observations of blocked ventriculoperitoneal (VP) shunt: a step toward better understanding of shunt obstruction and its removal. Br J Neurosurg 26:747-753, 2012

38. Stone JJ, Walker CT, Jacobson M, Phillips V, Silberstein HJ: Revision rate of pediatric ventriculoperitoneal shunts after 15 years. J Neurosurg Pediatr 11:15-19, 2013

39. Tubbs RS, Banks JT, Soleau S, Smyth MD, Wellons JC III, Blount JP, et al: Complications of ventriculosubgaleal shunts in infants and children. Childs Nerv Syst 21:48-51, 2005

40. Tuli S, O'Hayon B, Drake J, Clarke M, Kestle J: Change in ventricular size and effect of ventricular catheter placement in pediatric patients with shunted hydrocephalus. Neurosurgery 45:1329-1335, 1999

41. Whitehead WE, Riva-Cambrin J, Kulkarni AV, Wellons JC III, Rozzelle CJ, Tamber MS, et al: Ventricular catheter entry site and not catheter tip location predicts shunt survival: a secondary analysis of 3 large pediatric hydrocephalus studies. J Neurosurg Pediatr 19:157-167, 2017

42. Xenos C, Sgouros S, Natarajan K, Walsh AR, Hockley A: Influence of shunt type on ventricular volume changes in children with hydrocephalus. J Neurosurg 98:277-283, 2003 


\section{Disclosures}

The authors report no conflict of interest concerning the materials or methods used in this study or the findings specified in this paper.

\section{Author Contributions}

Conception and design: Iskandar, Kraemer. Acquisition of data: Iskandar, Kraemer, Koueik, Rebsamen, Luo, Saleh. Analysis and interpretation of data: Iskandar, Kraemer, Koueik, Salamat. Drafting the article: Iskandar, Kraemer. Critically revising the article: Iskandar, Kraemer, Koueik, Rebsamen, Hsu, Bragg. Reviewed submitted version of manuscript: Iskandar, Kraemer, Koueik, Hsu, Salamat, Luo, Saleh, Bragg. Approved the final version of the manuscript on behalf of all authors: Iskandar. Statistical analysis: Kraemer. Administrative/technical/material support: Iskandar. Study supervision: Iskandar.

\section{Supplemental Information}

Videos

Video 1. https://vimeo.com/275613721.

Video 2 . https://vimeo.com/275613759.

\section{Correspondence}

Bermans J. Iskandar: University of Wisconsin Hospitals and Clinics, Madison, WI. iskandar@neurosurgery.wisc.edu. 